\title{
A Comparative Study on Business Models of Municipal Wireless Cities in US and Sweden
}

\author{
Z Yang \\ Dept. of Signal Processing \\ Processing, Blekinge Institute \\ of Technology \\ SE-37225, Ronneby
}

Sweden

zya@bth.se
S Khamit

Dept. of Communication

Systems, Royal Institute of

Technology

SE-164 40, Stockholm

Sweden

saltanat.khamit@radio.kth.se
Abstract - In this paper, we will explore the existing operational "business models" for municipal wireless networks in US and Sweden. Based on the current paradigms of the North-American public wireless networks, we will investigate an emerging wireless city concept in Sweden to analysis this new business concept in the existing field. We will look into the relationship of different actors in various business models of the wireless cities in our selected case studies. This paper will aim to demonstrate a number of key considerations when designing and managing the business model of Municipal wireless networks as business-driven and public utility-driven services.

\section{INTRODUCTION}

Municipal (Muni) wireless network is mostly a wireless network to provide outdoor broadband access in the city area for residents, companies, tourists, public authorities. There are hundreds of cities worldwide, which have deployed and have plans to build wireless broadband networks over their territories. The main technology, which has been used to build the network, is Wi-Fi mesh technology. Cities around the world are exploiting the city wireless network to deliver egovernment services as well as promoting society interaction. It can either be regarded as a public utility-driven service by society with convenient broadband access at affordable prices, or as a business-driven information technology (IT) service to facilitate local business.

In this paper, we investigate existing and emerging business models implemented to support municipal wireless network in US and Sweden through case studies. This step helps to demonstrate the way to make the rationale and architecture of Muni wireless networks. We distinguish different business models based on the ownership of the network and service provision.

\section{EXISTING Business Model OF Muni WiRELESS City}

Most literature on Muni wireless network is rather vague on various business models, which are conceivable and/or used in practice. This typology is constituted by all potential combinations between two key roles, network ownership and network operation. Each role can be taken up by three different types of actors, e.g. public, private and group of others actors (private and/or public).

\author{
A Mohammed \\ Dept. of Signal Processing \\ Processing, Blekinge Institute \\ of Technology \\ SE-371 79, Karlskrona \\ Sweden \\ amo@bth.se
}

\author{
P Larson \\ Strategic Dev., Affärsverken \\ Karlskrona $A B$ \\ Box 530, SE-371 23, \\ Karlskrona \\ Sweden \\ peter.larson@affarsverken.se
}

We will follow the typology to fit real-life cases in US and Sweden [1]. In order to have a convincing outlook, we separate the ownership of network and service provision as shown in Figure 1. The most important business roles can be defined by owning physical assets and customer resources. Indeed, these business roles are often taken up by different actors. Operating the network infrastructure by itself is a secondary crucial role. Usually it is either combined with network ownership or with service provision. The type of ownership can be classified as follows: private, public, opensite and wholesale, as well as different combinations of them.

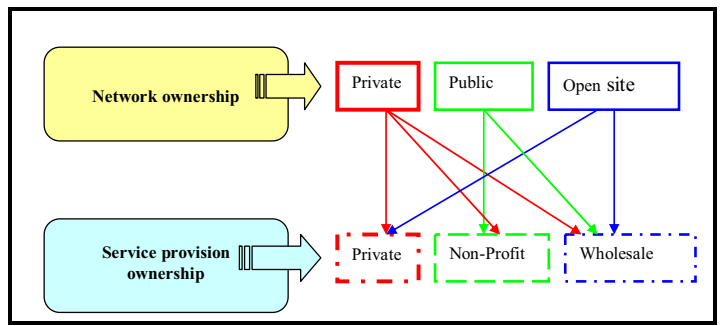

Figure 1. Business model for Muni municipal wireless network

\section{CASE STUdiES ON MUNI WIRELESS CITIES}

\section{Case study-Portland Wireless City, USA}

The business model of Portland wireless city can be interpreted as 'advertiser-supported' model [2]. The network is supported by "private-wholesale" type of business relations, where network assets belong to MetroFi, the main network provider. Free Web access services are supported by national and local advertisers. As an alternative, users who prefer an Internet access without advertisement can pay for premium services. Portland municipality becomes the major 'anchor tenant' for MetroFi's wireless network provider. The main advantage of this public network is to allow all municipal employees to have an access to the network with certain functionalities. Figure 2 gives an insight view of main actors' relations. Therefore, all components in "green" colour have been had by Portland's authority. However components in "pink" show only the influence to the outsourcing service providers, who provide advertising, consulting, customerhelpdesk support and etc.

Case study - wireless city of Karlskrona, Sweden

The city of Karlskrona in Sweden works with the wireless network operator - The Cloud - to provide the Muni wireless 


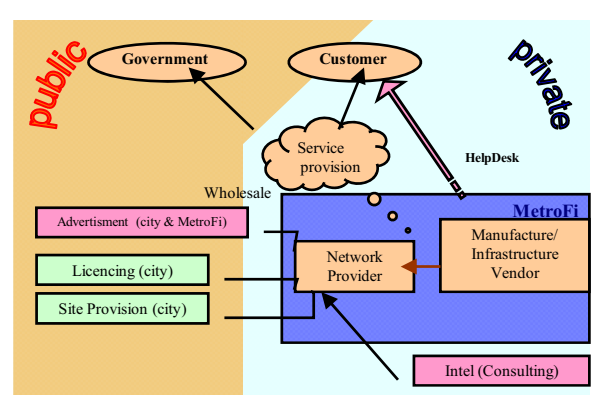

Figure 2. Business model of Portland Muni wireless City, USA

access [3]. In this case, a public-private partnership (also known as city-driven) business model in Figure 3 is implemented. The model is based on partnership collaborations. A core concept in the business model is the neutrality and openness, which allow the wireless network operator to work with a wide range of service providers and even mobile network operators. Since it is a municipalityowned fixed network operator that provides the backbone to the Muni wireless networks, the commune could have power over activities of the Muni wireless network operator to keep fair competitions between different service providers.

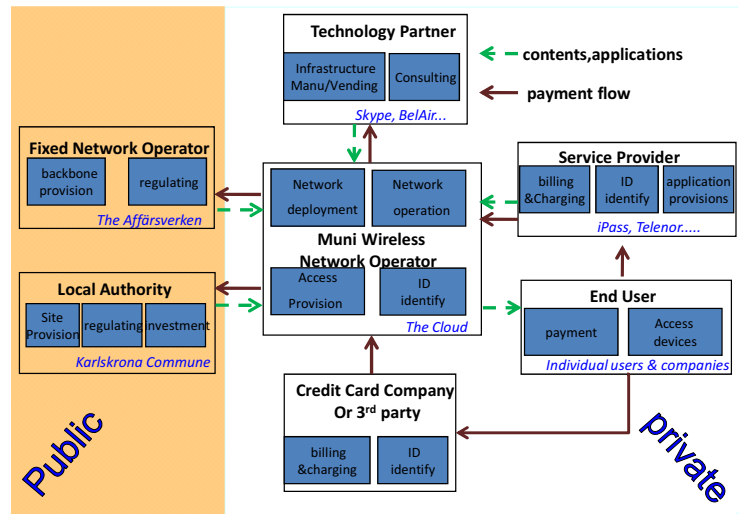

Figure 3. Business model of wireless city in Karlskrona, Sweden

\section{COMPARATIVE ANALYSIS ON CASE STUDIES}

There are some main similarities in selected two cases.

1) Municipal initiative. Wireless city can be regarded as a symbol of a city and facilitate local activities. In two cases, municipalities play important roles to take the initiative of building wireless cities based on local municipal profiles and demand.

2) Fair competition environment. A fair business environment is mostly expected by the municipality. Whether being forced or volunteered to open its network, the Muni network operator in two cases has provided opportunities for other ISPs to deliver services via its network. This could be regarded as an emerging idea to traditional concepts that a single company mono occupies all positions in the value chain.

3) Free access to public service and affordable price. Accessing to public services is free in both cases. It especially facilitates activities of visitors to obtain public information in these cities. Regular end users could have a reasonable price to access the network. In Portland, end users can even use the network for free if they agree to receive advertisement. In Karlskrona, the monthly subscription fee is in the same level if compared to major cable companies. However it gives endusers an outdoor internet access capability as a bonus.

4) Low investment for Municipality. In both cases, municipality can be regarded as a lossless actor in the market. It doesn't need to put much investment on the wireless network infrastructure, but gains privileges for its residents and local companies.

There are also some differences in selected two cases.

1) Influence and regulation from municipality. In the Karlskrona case, the municipality only forms a partnership with the network operator and provides the core backbone to Muni wireless network. Thus it is highly involved in the network operation by delivering traffic through its fiber network. Furthermore, the municipality of Karlskrona has a stronger influence on activities of Muni wireless network operator. For example, it could also introduce other Muni network operator as a competitor to balance the power of The Cloud.

2) Customer relationship with end users. In Portland, the MetroFi is acting mainly as an ISP and building a direct relationship with end users. However The Cloud in Karlskrona avoids establishing a direct and long-term relationship with end-users in order to keep its neutral position for other ISP as its customers. Revenue of The Cloud is mainly from its partner rather than direct payment from end users.

3) Different types of collaboration with service providers. In the case of Karlskrona, the Muni network operator has actively established extensive partnership with different service providers. In the case of Portland, the Muni network operator is acting actively like a traditional ISP. It may also be forced to provide access for other ISPs accoding to agreement.

\section{SUMMARY AND CONCLUSION}

The concept of Muni wireless city can not be treated as a pure business case, since it has public and non-profit attributes. Key elements of successfully implementing a business model are fairness and openness based on our investigations. City profile information, such as location, population, is also crucial. Base on our investigations, the public-private business model with partnership collaborations implemented by the city of Karlskrona has more advantages on balancing benefits of all the actors involved in the business model in a long-term perspective.

\section{REFERENCE}

[1] F. Bar and N. Park, "Municipal Wi-Fi Networks: The Goals, Practices, and Policy Implications of the US Case," Communications \& Strategies, vol. 61(1st quarter 2006), pp. 107-126, 2006.

[2] http://www.metrofi.com.

[3] N. Leon, "The Well Connected City," http://www.thewirelessevent.com, 2006. 